\title{
Editorial
}

\section{Progress with reducing mortality from organophosphorus insecticide poisoning}

\author{
Michael Eddleston ${ }^{1,2,3 *}$ \\ ${ }^{1}$ Pharmacology, Toxicology and Therapeutics, University/BHF Centre for Cardiovascular Science, \\ University of Edinburgh \\ ${ }^{2}$ Department of International Health, Immunology and Microbiology, University of Copenhagen \\ ${ }^{3}$ South Asian Clinical Toxicology Research Collaboration (SACTRC), Sri Lanka
}

Keywords: Organophosphorus; Insecticide poisoning

Copyright: (C) 2014 Eddleston M. This is an open access article distributed under the Creative Commons Attribution License, which permits unrestricted use, distribution, and reproduction in any medium, provided the original work is properly cited.

*Correspondence: M.Eddleston@ed.ac.uk

Cite this article as: Eddleston M. Progress with reducing mortality from organophosphorus insecticide poisoning. Anuradhapura Medical Journal 2014; 8(1):1-4.

DOI: http://dx.doi.org/10.4038/amj.v8i1.6751

Twenty years ago, the medical and intensive care wards of Anuradhapura General Hospital were filled with patients severely poisoned by agricultural pesticides, particularly organophosphorus (OP) insecticides (1). After bans of parathion and methyl-parathion in the 1980s, $(2,3)$ the most popular pesticides in agriculture and self-harm were the still highly toxic WHO Class IB (4) insecticides methamidophos ('Tamaron') and monocrotophos (2). These pesticides killed people quickly, from acute respiratory arrest and, perhaps after monocrotophos, from distributive cardiovascular shock. Many patients died in the community, before they were able to reach medical care (2).

The Registrar of Pesticides of the Department of Agriculture acted to reduce the import of all Class I pesticides, including methamidophos and monocrotophos, by $25 \%$ each year from 1992 until a complete ban came into force in 1995.(2, 3) This was the first such ban worldwide. Deaths from OP insecticide poisoning in Anuradhapura wards fell markedly but were unfortunately soon replaced by cases of severe endosulfan poisoning. This less inherently toxic insecticide - a WHO Class II toxicity organochlorine - was however very hard to treat and deaths due to status epilepticus became common. So this pesticide too was banned across the Island by the Registrar of Pesticides in 1998 and case numbers quickly faded away (2).

Ten years ago, the most important causes of pesticide poisoning in the Anuradhapura medical wards were the relatively less toxic WHO Class II OP insecticides, chlorpyrifos, dimethoate, and fenthion (5). These pesticides were about ten-fold less potent (in rat studies) than the older Class I OPs and patients now survived to secondary hospitals admission. But dimethoate was particularly severe, killing many patients from cardiovascular shock unresponsive to very large doses of atropine and adrenaline 12 to $48 \mathrm{hrs}$ post-ingestion $(5,6)$. However, despite an apparently large numbers of deaths in the Anuradhapura medical wards, there were now many fewer deaths in the community and far fewer deaths overall (7). Between 1995 and 2005, the overall suicide rate in Sri Lanka fell by $50 \%$ - due almost completely to a marked fall in the case fatality from pesticide poisoning (7).

Then these Class II OP insecticides were banned, along with two herbicides that were commonly lethal in overdose: paraquat and propanil. Over the last two to three years, there have been far fewer seriously ill pesticidepoisoned patients admitted to Teaching Hospital Anuradhapura than ever before. The case fatality for pesticide poisoning has fallen from around $14 \%$ in 2002 to just a few percent currently. The majority of this change is almost certainly due to the bans instigated by the Registrar of Pesticides. However, some of the reduction has come from better treatment of OP insecticide poisoned patients. The two key antidotes for OP insecticide poisoning have not changed in 60 years. Atropine was first used in the USA during the $1950 \mathrm{~s} ;(8)$ it is still the primary antidote for OP poisoning (9). However, the collaborative clinical work performed in Anuradhapura and Polonnaruwa General Hospital medical wards in 2002-3 showed how poor the then international guidelines for atropine dosing were - sometimes recommending regimens that might take over 12 hours to give adequate atropine, leaving patients dangerously unstable (10). A protocol was developed (11) that was tested in an RCT in Bangladesh - this showed a 
marked reduction in time to stabilisation and a remarkable drop in mortality from 22.5 to $8 \%$ (12). A recent review has shown how the North Central Province (NCP) work has been globally adopted (13).

The other antidote - pralidoxime (or the related obidoxime) (14) - is less unanimously appreciated. Developed in the USA in the 1950 s, $(15,16)$ Janaka de Silva and Nimal Senanayake reported in 1992 that a shortage of pralidoxime in Peradeniya had no apparent effect on outcome (17). WHO International Programme on Chemical Safety (IPCS)-affiliated toxicologists responded that the dose being used in Sri Lanka was too low $(9,18)$. Yet, it reality, there was almost no high quality evidence for clinical benefit from oximes, especially after selfpoisoning with WHO Class IB and II toxicity OP insecticides (19). In 2004, an RCT was set up in Anuradhapura and Polonnaruwa to test the high dose pralidoxime chloride regimen recommended by the WHO IPCS group. Unfortunately, no evidence of benefit was found; in particular, in addition to offering no obvious mortality benefit, it did not reduce the need for intubation or shorten the duration of ventilation (20).

This finding was in marked contrast to that of Kirti Pawar and colleagues in Maharashtra who published a RCT in 2006 of 200 patients with moderate severity poisoning;(21) this study found that a high dose of pralidoxime iodide was better than a lower dose for all outcomes, including death. This difference is surprising and might be due to patient selection in India and also the high-level intensive care that was offered to nearly all patients - $66 \%$ of the Indian patients were intubated at baseline compared to $17 \%$ in NCP, despite being less unwell. The current role for oximes in OP insecticide poisoning is unclear ; 22,23$)$ further studies are required to determine whether benefit can be established using neurophysiological assays to identify patients responding and to identify better dosing regimens.

In the meantime, are there other possible treatments that could be simply and rapidly introduced into clinical practice? $(24,25)$ One such treatment might be nebulised salbutamol.

Although atropine is effective at stopping production of bronchial fluid during the cholinergic crisis, it does not increase its removal from alveoli. The tap is turned off but no effort is made to remove fluid from the lungs. A treatment that increases removal, to complement atropineinduced cessation of production, should speed the return of effective oxygen exchange and speed resuscitation. A single nebulised dose of the beta-adrenergic agonist salbutamol may do this since it increases alveolar fluid removal via the epithelial sodium channel (26). Nebulised salbutamol is available in rural hospitals worldwide and could easily be given alongside oxygen and atropine during initial resuscitation.

OP-induced neuromuscular junction (NMJ) dysfunction causes patients to require ventilation for several weeks, leaving them at high risk of death from complications. Its pathophysiology is uncertain; however, since it occurs despite effective muscarinic blockade with atropine, it is thought to be due to overstimulation of synaptic NMJ nicotinic receptors by excess acetylcholine, their subsequent down regulation, and neurotransmission failure $(27,28)$. No specific treatment exists.

We have recently established a minipig model of OPinduced NMJ dysfunction (29) and tested whether nicotinic antagonism is protective. Preliminary studies have shown that the neuromuscular blocker rocuronium protects the NMJ: removal with its antidote resulted in complete recovery of function. This suggests that administration of a neuromuscular blocker in patients requiring early ventilation may prevent nicotinic overstimulation and NMJ dysfunction, shortening the duration of ventilation and preventing complications.

Both salbutamol and a neuromuscular blocker, such as rocuronium or vecuronium, could now be tested in small RCTs to assess for any evidence of benefit. Such evidence should trigger dose finding studies and then formal Phase II/III RCTs to determine their cost-effectiveness in OP insecticide poisoned patients. These studies could be performed in NCP; however, due to the reduction of cases following the highly effective agricultural and public health interventions, these studies should also include other clinical centres in Asia where OP pesticide poisoning remains a major problem.

It may also be possible to work outside the medical and intensive care wards of Anuradhapura and Polonnaruwa, to improve clinical care of patients before they reach the main hospitals. Many patients become symptomatic before presenting to hospital. For some, respiratory arrest occurs and death ensues before intubation is possible; others present to a rural hospital with severe cholinergic features and die before onward transfer. An intervention that stabilised patients in the first hour after poisoning has the potential to save many lives.

Atropine auto-injectors are used widely by military and by adult and paediatric populations at risk of OP nerve agent exposure and have an excellent safety profile (30). Administration of atropine early in the community, via an auto-injector, to stabilise patients during transfer to hospital might save many lives. Community level studies will be required to determine whether people might accept this intervention and where the auto-injectors could be stored in the village to allow easy access.

Interventions might also work in rural hospitals, to improve the safety of patient transfers to Anuradhapura and Polonnaruwa. Poisoned patients often lose consciousness and aspirate gastric contents (31). Ideally, unconscious patients should be intubated before transfer. However, doctors in the smaller rural hospitals are often junior and intubate rarely, resulting sometimes in delayed and sub-optimal intubation due to infrequent practice. An intervention to safeguard an unconscious patient's airway that did not require intubation - such as a supraglottic airway (SGA)(32) - could markedly reduce the risk of aspiration and complications associated with inexperienced intubation. It would benefit those poisoned by any pesticide, with or without alcohol intoxication, reduce delays in transfer, and strengthen the system for 
transfer of all unconscious patients. Both these presecondary hospital interventions could be tested in a factorial community cluster RCT.

Clinical trials in Sri Lanka, and particularly in Anuradhapura and Polonnaruwa, have guided worldwide clinical practice in pesticide poisoning over the last 10-20 years. Future clinical trials could continue to shape global clinical practice. At the same time, adoption of Sri Lanka's successful pesticide registration processes across rural Asia should markedly reduce global suicide.

\section{Acknowledgements}

ME is a Scottish Senior Clinical Fellow and Lister Prize Fellow; much of the clinical trial work performed in NCP was supported by the Wellcome Trust. ME thanks the academic, medical, and nursing staff of the Province for their collaboration and support in performing these studies, and for the patients for agreeing to enter trials. He also thanks his many Sri Lankan and international collaborators for their support.

\section{References}

1. Eddleston M, Sheriff MHR, Hawton K. Deliberate self-harm in Sri Lanka: an overlooked tragedy in the developing world. BMJ 1998; 317:133-5.

2. Roberts DM, Karunarathna A, Buckley NA, Manuweera G, Sheriff MHR, Eddleston M. Influence of pesticide regulation on acute poisoning deaths in Sri Lanka. Bull World Health Organ 2003; 81:789-98.

3. Pearson M, Zwi AB, Buckley NA, Manuweera G, Fernando R, Dawson AH, et al. Policymaking 'under the radar': a case study of pesticide regulation to prevent intentional poisoning in Sri Lanka. Health Policy Plan 2013 Dec 20.

4. World Health Organization. The WHO recommended classification of pesticides by hazard and guidelines to classification: 2009. Geneva: WHO; 2010.

5. Eddleston M, Eyer P, Worek F, Mohamed F, Senarathna L, von Meyer L, et al. Differences between organophosphorus insecticides in human self-poisoning: a prospective cohort study. Lancet 2005; 366:1452-9.

6. Davies JOJ, Roberts DM, Eyer P, Buckley NA, Eddleston M. Hypotension in severe dimethoate self-poisoning. Clin Toxicol 2008; 46:880-4.

7. Gunnell D, Fernando R, Hewagama M, Priyangika WDD, Konradsen F, Eddleston M. The impact of pesticide regulations on suicide in Sri Lanka. Int J Epidemiol 2007; 36:1235-42.

8. Freeman G, Epstein MA. Therapeutic factors in survival after lethal cholinesterase inhibition by phosphorus pesticides. $N$ Engl J Med 1955; 253:266-71.

9. Johnson MK, Jacobsen D, Meredith TJ, Eyer P, Heath AJW, Ligtenstein DA, et al. Evaluation of antidotes for poisoning by organophosphorus pesticides. Emergency Medicine 2000; 12:22-37.

10. Eddleston M, Buckley NA, Checketts H, Senarathna L, Mohamed F, Sheriff MHR, et al. Speed of initial atropinisation in significant organophosphorus pesticide poisoning - a systematic comparison of recommended regimens. $J$ Toxicol Clin Toxicol 2004; 42:865-75

11. Eddleston M, Dawson A, Karalliedde L, Dissanayake W, Hittarage A, Azher S, et al. Early management after self-poisoning with an organophosphorus or carbamate pesticide - a treatment protocol for junior doctors. Crit Care 2004; 8:R391-R397.

12. Abedin MJ, Sayeed AA, Basher A, Maude RJ, Hoque G, Faiz MA. Open-label randomized clinical trial of atropine bolus injection versus incremental boluses plus infusion for organophosphate poisoning in Bangladesh. J Med Toxicol 2012; 8(2):108-17.

13. Connors NJ, Harnett ZH, Hoffman RS. Comparison of current recommended regimens of atropinization in organophosphate poisoning. J Med Toxicol 2013;Jul:1-5.

14. Eyer P. The role of oximes in the management of organophosphorus pesticide poisoning. Toxicol Rev 2003; 22:165-90.

15. Wilson IB, Ginsburg B. A powerful reactivator of alkylphosphate-inhibited acetylcholinesterase. Biochim Biophys Acta 1955; 18(1):168-70.

16. Namba T, Hiraki K. PAM.(pyridine-2-aldoxime methiodide) therapy of alkylphosphate poisoning. JAMA 1958; 166:1834-9.

17. De Silva HJ, Wijewickrema R, Senanayake N. Does pralidoxime affect outcome of management in acute organophosphate poisoning?. Lancet 1992; 339:1136-8.

18. Johnson MK, Vale JA, Marrs TC, Meredith TJ. Pralidoxime for organophosphorus poisoning [letter]. Lancet 1992; 340:64.

19. Eddleston M, Szinicz L, Eyer P, Buckley N. Oximes in acute organophosphorus pesticide poisoning: a systematic review of clinical trials. $Q J$ Med 2002; 95:275-83.

20. Eddleston M, Eyer P, Worek F, Juszczak E, Alder N, Mohamed F, et al. Pralidoxime in acute organophosphorus insecticide poisoning--a randomised controlled trial. PLoS Med 2009; 6(6):e1000104. 
21. Pawar KS, Bhoite RR, Pillay CP, Chavan SC, Malshikare DS, Garad SG. Continuous pralidoxime infusion versus repeated bolus injection to treat organophosphorus pesticide poisoning: a randomised controlled trial. Lancet 2006; 368:2136-41.

22. Peter JV, John G. Management of acute organophosphorus pesticide poisoning. Lancet 2008; 371(9631):2170-1.

23. Buckley NA, Eddleston M, Li Y, Bevan M, Robertson J. Oximes for acute organophosphate pesticide poisoning. Cochrane Database Syst Rev 2011; 2:CD005085.

24. Peter JV, Moran JL, Graham PL. Advances in the management of organophosphate poisoning. Expert Opin Pharmacother 2007; 8(10):1451-64.

25. Eddleston M, Buckley NA, Eyer P, Dawson AH. Medical management of acute organophosphorus pesticide poisoning. Lancet 2008; 371:597-607.

26. Ware LB, Matthay MA. The acute respiratory distress syndrome. N Engl J Med 2000; 342:1334-49.

27. Senanayake N, Karalliedde L. Neurotoxic effects of organophosphate insecticides: an intermediate syndrome. $N$ Engl J Med 1987; 316:761-3.

28. De Bleecker JL. The intermediate syndrome in organophosphate poisoning: an overview of experimental and clinical observations. J Toxicol Clin Toxicol 1995; 33:683.

29. Eddleston M, Street JM, Self I, Thompson A, King T, Williams N, et al. A role for solvents in the toxicity of agricultural organophosphorus pesticides. Toxicology 2012; 294:94-103.

30. Sandilands EA, Good AM, Bateman DN. The use of atropine in a nerve agent response with specific reference to children: are current guidelines too cautious?. Emerg Med J 2009; 26(10):690-4.

31. Eddleston M, Mohamed F, Davies JOJ, Eyer P, Worek F, Sheriff MHR, et al. Respiratory failure in acute organophosphorus pesticide self-poisoning. $Q J$ Med 2006; 99:513-22.

32. Ostermayer DG, Gausche-Hill M. Supraglottic airways: the history and current state of prehospital airway adjuncts. Prehosp Emerg Care 2013;18: 106-15.

Submit your next Manuscript to

Anuradhapura

Medical Journal

Submit your manuscript at

WwW.sljol.info/index.php/AMJ/ 